\title{
EDUCATIONAL
} TECHNOLOGY

\section{The efficiency of educational communications networks: ATS-1 as a quasi-mass medium}

\author{
James C. Lange \\ Research Fellow \\ University of Western Australia \\ Nedlands, Western Australia
}

\begin{abstract}
The ATS-1 satellite has been used for educational teleconferencing networks in the Pacific Islands for the past decade. It has been criticised as inefficient, but these criticisms are largely based on a misunderstanding of the limitations of the satellite, which make it what Regan (1978) calls a "quasi-mass medium". This study analyses the content of ATS-1 traffic to examine both the strengths and weaknesses of its networks, and suggests ways to improve their operation.
\end{abstract}

\section{Introduction}

In 1966, NASA launched its first geosynchronous Applications of Technology Satellite (ATS-1). In 1971, ATS-l time was granted to the PanPacific Education and Communication Experiment via Satellite (PEACESAT) under the supervision of the University of Hawaii Communication Department (Bystrom and Yuen, 1971). This experimental network was designed as an audio-conferencing system which would allow citizens of Pacific islands to talk with other Pacific islanders who shared similar interests. Since its inception, PEACESAT has mounted regular educational conferences on a wide range of subjects, putting together vulcanologists, primary school classes, physicians, church groups, college deans, farmers, and family planning specialists, to name just a few.

In 1974, the University of the South Pacific (USP) opened an audioconferencing network on ATS-1 designed to support correspondence education among its nine member nations through tale-tutorials and administrative exchanges to facilitate enrolment, assignment flow, grading and materials supply (Bensted, Northcott and McMechan, 1975). In 1980, the USP network supported 30 degree courses for over 1200 students, witn over 4800 class enrollments (USP Extension Services, 1981). In 1976, Miami 
University and the Hawaii Institute of Geophysics established the OCEAN Network, to communicate with research vessels at sea (Eden and Brown, 1976). In 1980 the Pacific Post-Secondary Education Council established an educational network in Micronesia, in place of the old Department of the Interior Satellite project. (Lang,1985). In 1981, several Australian educational institutions stations inaugurated a fifth ATS-1 network for experimentation with satellite tele-conferencing, in preparation for the Australian domestic satellite due to be launched in 1985.

Despite these successes, the ATS-1 satellite has been criticised as an "elitist" medium (Davey, 1983), which is underutilised (Boker, 19d2), by mostly "haole" (Caucasian) outsiders. (Plante, 1980). Until recently, these criticisms were thought to be academic, since the satellite was consuming its station-keeping fuel so rapidly that it was expected to go out of service by the end of 1983. .However, NASA moved ATS-1 to a new orbit (roughly 164 degrees east longitude), and now expects the satellite to hold its position until at least 1993. The new orbit puts the satellite outside the reach of the United States mainland, but brings it into line-of-sight for all of Australia and much of Pacific Asia. This new lease on life as a peculiarly Pacific resource has stimulated new interest in the satellite, and required ATS-1 users to examine the earlier criticisms to determine their validity and to discover now any failings might be corrected. This study examines the content of the ATS-1 networks, and makes some suggestions for improvements.

\section{Method}

Some 50 ATS-1-1 terminals span 1 time zones, which makes time that includes a part of the normal working day at all terminals a rare premium. The afternoon portion of the PEACESAT network (0300-0500 Greenwich Mean Time) is considered "prime-time" for the Pacific. The traffic in this time block was recorded for the last two weeks of August of 1982, and each transmission (or "over") was coded by station transmitting, person speaking (network staff or participant), topic (network administration or teleconference content), participation mode point-to-point or multiterminal teleconference), signal quality and the transmission duration in seconds. This sample was extremely thorough, in that each transmission was coded, but it covered only two weeks of $1 / 2$ of a single ATS-1 network, which made generalisation difficult.

To get a generalisable picture of all five networks, a full month's content was needed. Since ATS-1 uses at least 14 hours a day, six days a week, this meant a sample of about 550 hours. In the first study, timing the entire body of content (by two separate coders, to check inter-rater reliability) required over 200 working hours for 30 hours of tape: a work-to-content ratio of 7 to 1 . The full month sample would thus require 60 person-weeks of coder time, which was far beyond the research budget available. But if each transmission is scored as a unit, without being precisely timed, the content coding can be done in real-time by terminal operators who are 
already on payroll. However, simply counting the number of transmissions under-estimates the time used in a given category when the average transmission time is long, and over-estimates it when the average time is short.

Table 1: Duration versus Frequency Measures

\begin{tabular}{lccc} 
& $\begin{array}{c}\text { \% time } \\
(\mathrm{N}=22.9 \mathrm{hr})\end{array}$ & $\begin{array}{c}\text { mean } \\
\text { time }\end{array}$ & $\begin{array}{c}\text { \% overs } \\
(\mathrm{N}=3010)\end{array}$ \\
\hline Polynesia & 27.2 & 29.4 & 25.3 \\
Hawaii & 25.8 & 35.9 & 19.7 \\
New Zealand & 23.5 & 25.7 & 25.0 \\
Australia & 10.6 & 24.6 & 11.8 \\
Melanesia & 8.4 & 20.8 & 11.0 \\
Micronesia & .5 & 17.0 & 7.2 \\
\hline
\end{tabular}

Switching from saturation sampling to random sampling within fixed blocks overcomes this problem, since the probability of sampling a given category of transmission is based on its summed duration rather than its frequency. For example, if category $\mathrm{A}$ is typically 10 seconds long and occurs 6 time more frequently than category B, which is 60 seconds long, the two categories have an equal chance of being included in the sample of a given time unit, provided that the time unit is significantly longer than the longest transmission (in this case, 60 seconds).

The active ATS- 1 day, from 1800 to 0800 Greenwich Mean Time, was divided into half-hour segments, and one sample was taken each half-hour from June 1 to June 30, 1983. The precise time of sample within each halfhour block was chosen from a table of random numbers. This method gives a very close approximation of the saturation sample, as Table 2 indicates.

Table 2: Random versus Saturation Samples

\begin{tabular}{lcc} 
& $\begin{array}{c}\text { Saturation Sample } \\
\% \text { of Peacesat } \\
\text { Afternoon time }\end{array}$ & $\begin{array}{c}\text { Random Sample } \\
\% \text { of Peacesat } \\
\text { Afternoon Time }\end{array}$ \\
\hline Polynesia & 27.2 & 21.4 \\
Hawaii & 25.8 & 27.1 \\
New Zealand & 23.5 & 21.6 \\
Australia & 10.6 & 13.3 \\
Melanesia & 8.4 & 10.5 \\
Micronesia & 4.5 & 6.1 \\
\hline Staff & 55.2 & 54.7 \\
Participants & 44.8 & 45.3 \\
\hline Administration & 48.9 & 47.0 \\
Content & 51.1 & 53.0 \\
\hline
\end{tabular}




\section{Results}

The first test of any communications network is its scheduling efficiency, or the ratio of available time to time actually used. ATS-1, during the hours sampled, shows an overall scheduling efficiency of $51.4 \%$, with scheduled networks running from a low of 23.9\% (Hawaii Institute of Geophysics' Ocean Net) to a high of $72.5 \%$ (PEACESAT).

Table 3: ATS-1 Scheduling Efficiency (Mon-Sat, June 1-30, 1983: 1800-0800 GMT)

\begin{tabular}{lccc} 
& $\begin{array}{c}\text { Hours } \\
\text { sampled }\end{array}$ & $\begin{array}{c}\text { Hours } \\
\text { used }\end{array}$ & $\begin{array}{c}\% \text { of } \\
\text { use }\end{array}$ \\
\hline Micronet & 44 & 24.5 & 56.1 \\
Kangaroo Net & 40 & 23.0 & 57.5 \\
USP Net & 89 & 56.0 & 62.9 \\
Peacesat Net & 95 & 64.5 & 72.5 \\
Ocean Net & 44 & 10.5 & 23.9 \\
Open Time & 47 & 6.0 & 12.8 \\
\hline Total & 359 & 184.5 & 51.4 \\
\hline
\end{tabular}

Administrative efficiency, or "throughput", is the ratio of time actually used to the time used for content, as opposed to administrative functions; ie. the user message which actually gets through. Our ATS-1 sample had an overall throughput of $32.6 \mathrm{i}$, with a low of $12.5 \%$ for Ocean Net and a high of $46 \%$ for the University of the South Pacific Network.

Table 4: Administrative Efficiency

\begin{tabular}{lccc} 
& $\begin{array}{c}\% \text { of time } \\
\text { actually used }\end{array}$ & $\begin{array}{c}\% \text { used } \\
\text { for content }\end{array}$ & $\begin{array}{c}\% \\
\text { throughput }\end{array}$ \\
\hline Overall & 51.4 & 63.4 & 32.6 \\
Micro Net & 56.1 & 77.6 & 43.5 \\
Kangaroo Net & 57.5 & 50.0 & 28.8 \\
USP Net & 62.9 & 73.2 & 46.0 \\
Peacesat Net & 72.5 & 58.1 & 42.1 \\
Ocean Net & 23.9 & 52.4 & 12.5 \\
Open Time & 12.8 & 41.7 & 5.3 \\
\hline
\end{tabular}

Error rate, the third common measure of communication efficiency, is difficult or impossible to measure on voice networks, since oral communication embeds the "message" in a highly redundant and ambiguous code. However, measuring signal quality subjectively, ATS-1 operators report signals as less than "loud and clear" $40.5 \%$ of the transmission time. This is a severe limitation on the potential of the satellite, since, even the best ideas, presented in the best manner, under the most precise schedule will be wasted if the signal quality is so poor that the participants cannot separate the channel noise from the words (or data) being transmitted. 
Within a given network, several measures of design efficiency can be computed to measure how well the network meets its own stated objectives. The proportion of "appropriate" or design-targeted content can be seen as a measure of goal achievement. The Micronesia network, the University of the South Pacific (USP) network, and the PEACESAT network all are intended to function in a multi-nodal teleconferencing mode rather than a point-to- point mode that would compete with common carriers. They are also designed to serve participants, rather than terminal operators, and to involve Pacific Islanders, rather than Caucasians. The Kangaroo Network, linking Australian terminals, shares these design goals, with the exception of the need to include islanders in preference to Caucasians.

When the goal achievement percentages (see Table 5) are multiplied, the resultant goal achievement ratio concatenates the system failure, since it falsely assumes exclusivity of categories: for example, some nonparticipant staff are islanders. However, in analysing communications networks it is always preferable to under- estimate, rather than overestimate, one's own success. Kangaroo net $(59.3 \%)$ has the best goal achievement, since it has one less category to satisfy, while PEACESAT $(16.0 \%)$ does the worst at meeting its own very high goals.

Table 5: Design Efficiency

\begin{tabular}{lccccc} 
& $\begin{array}{c}\% \text { of } \\
\text { Micronet } \\
(\mathrm{N}=24.5)\end{array}$ & $\begin{array}{c}\% \text { of } \\
\text { Kangaroo } \\
(\mathrm{N}=23)\end{array}$ & $\begin{array}{c}\% \text { of } \\
\text { USP Net } \\
(\mathrm{N}=56)\end{array}$ & $\begin{array}{c}\% \text { of } \\
\text { Peacesat } \\
(\mathrm{N}=64.5)\end{array}$ & $\begin{array}{c}\% \text { of } \\
\text { Total }\end{array}$ \\
\hline Teleconference & 80.0 & 85.2 & 87.7 & 73.2 & 73.1 \\
x Participants & 53.1 & 69.6 & 52.7 & 50.4 & 50.1 \\
x Islanders & 38.8 & $\mathrm{~N} / \mathrm{A}$ & 53.6 & 43.4 & 39.0 \\
\hline & 16.5 & 59.3 & 24.8 & & \\
$\mathrm{x}$ Throughput & 43.4 & 28.8 & 46.0 & 42.1 & 32.6 \\
\hline Success Index $(\mathrm{SI})$ & .07 & .17 & .11 & .07 & .05 \\
\hline
\end{tabular}

Multiplying the goal achievement index by throughput gives a success index (SI) which can be used to compare networks. It cannot be interpreted as the percentage of network time that is used appropriately since, in addition to the severe under-estimation already contained in the goal achievement index, the SI also ignores some systemic amelioration, for example, the proportion of participants is higher in content traffic than in administrative traffic. As Table 5 shows, the Success Index runs from a low of .07 (PEACESAT) to high of .17 (Kangaroo Net).

The proportion of time a station speaks is an indication of network dominance. With 40 terminals active in the 369 half-hour sample, cell size for individual terminals was frequently too small to be reliable, so stations have been aggregated into regions. (See Table 6) As expected, Micronesia dominates its own net, as does Australia and Fiji (USP). In fact, when the University of the South Pacific stations are aggregated, they account for 
$82.7 \%$ of the USP Net. Hawaii terminals are highly vocal in all other networks, taking $54.7 \%$ of Micronesian time, 23.9 (of Australian time and $20.2 \%$ of PEACESAT. Polynesian terminals are inactive outside the USP and PEACESAT networks. Polynesia's high activity in PEACESAT is partially due to Raratonga, which acts as network control in the morning hours (1300-2100) and for technical sessions. Similarly, New Zealand is disproportionately active in the PEACESAT network where it acts as network control in the afternoon (0300-05005. Melanesia is not very vocal in any of the four networks. The "other" category aggregates research vessels, Australian occasional stations and transmission from the United States mainland, patched in through ATS-5.

Table 6: Network Dominance

\begin{tabular}{lccccc} 
& $\begin{array}{c}\% \text { of } \\
\text { Micronet } \\
(\mathrm{N}=49)\end{array}$ & $\begin{array}{c}\% \text { of } \\
\text { Kangaroo } \\
(\mathrm{N}=46)\end{array}$ & $\begin{array}{c}\% \text { of } \\
\text { USP Net } \\
(\mathrm{N}=112)\end{array}$ & $\begin{array}{c}\% \text { of } \\
\text { Peacesat } \\
(\mathrm{N}=129)\end{array}$ & $\begin{array}{c}\% \text { of } \\
\text { Total } \\
(\mathrm{N}=369)\end{array}$ \\
\hline Hawaii & 34.7 & 23.9 & 1.8 & 20.2 & 22.0 \\
Polynesia & -- & -- & 25.9 & 33.3 & 19.8 \\
Fiji & 2.0 & -- & 56.3 & 3.1 & 18.4 \\
Australia & 12.2 & 67.4 & 3.6 & 9.3 & 14.9 \\
New Zealand & -- & 2.2 & 2.7 & 25.6 & 10.0 \\
Micronesia & 46.9 & -- & -- & 3.1 & 7.6 \\
Melanesia & 2.0 & 2.2 & 7.1 & 5.4 & 5.4 \\
Other & 2.0 & 4.3 & 2.7 & -- & 1.9 \\
\hline
\end{tabular}

The proportion of available hours during which regions participate in a given network (See Table 7) is some indication of the interest they have in that network though it also may be a reflection of an assigned task. For example, Hawaii's extremely high activity in the Micronesia network comes form its role in providing telephone patching to bring participants in Washington, DC., into discussions on political status in the Federated States of Micronesia, and Australia's activity in Micronesia is due, in a large part, to twice weekly computer transmission experiments which are chaired by the South Australia College of Advanced Education at Magill.

Table 7: Network Participation

\begin{tabular}{lccccc} 
& $\begin{array}{c}\% \text { of } \\
\text { Micronet } \\
(\mathrm{N}=88)\end{array}$ & $\begin{array}{c}\% \text { of } \\
\text { Kangaroo } \\
(\mathrm{N}=80)\end{array}$ & $\begin{array}{c}\% \text { of } \\
\text { USP Net } \\
(\mathrm{N}=178)\end{array}$ & $\begin{array}{c}\% \text { of } \\
\text { Peacesat } \\
(\mathrm{N}=190)\end{array}$ & $\begin{array}{c}\% \text { of } \\
\text { Total } \\
(\mathrm{N}=718)\end{array}$ \\
\hline Hawaii & 80.7 & 31.3 & 7.3 & 64.2 & 42.6 \\
Polynesia & 5.7 & 17.0 & 76.4 & 78.9 & 44.2 \\
Fiji & 2.3 & 13.8 & 70.8 & 34.2 & 29.8 \\
Australia & 20.5 & 71.3 & 13.5 & 31.6 & 22.8 \\
Melanesia & 3.4 & 5.0 & 50.6 & 31.1 & 22.1 \\
New Zealand & 3.4 & 20.0 & 6.7 & 45.3 & 16.9 \\
Micronesia & 68.2 & 2.5 & 2.2 & 22.6 & 15.9 \\
\hline
\end{tabular}




\section{Discussion}

For those interested in distributive equity, the balance among users (Tables 6 and 7) can be seen as a measure of the success of a given communication network, although this is a tricky issue. Most communications networks need a control centre, just as most groups need a leader, to set schedules, co-ordinate traffic and arbitrate among competing interests. Hence, it is inevitable that one or two stations will speak more than most others. Secondly, through the ATS-1 network, managers see the satellite as having great potential for expanding interregional co-operation in the Pacific islands. It does not follow that the people of, say, Melanesia see any need to participate in Micronesian conferences, or vice-versa. Finally, the lack of participation of a given region in a given network may be less an indication of interest in another region than of the failure of the network to include anything that is of interest to potential out-region participants. Any real improvements in the balance among users will depend on networks offering conference sessions that are of greater interest to other regions, on their making the terminal staff in other regions aware of these offerings, and on the terminal staff making an effort to share this knowledge with their communities. In short, this is an internal network problem.

The scheduling efficiency of the ATS-1 satellite is really quite low, considering that this sample included only the day-time hours. From 0800to 1800 , the satellite is essentially unused, although there are plans to begin using this time for course delivery in Micronesia (0800-0930) for education and radio broadcasting in Australia (0930-1100), for Asian terminals (1100 to 1300) and for unattended computer store \& forward traffic (1300-1700). However, it is clear that better use needs to be made of open time and of Ocean network time. Furthermore, the scheduling authority should do an hour-by-hour analysis and look for other users of time slots which go consistently unused. The PEACESAT network uses $72.5 \%$ of its time, which indicates that a scheduling efficiency of $75 \%$ is a reasonable goal for an ATS-1 network.

Administrative efficiency is also low. Any network requires some time for scheduling, polling the net, and copy checks. Furthermore, ATS-1 networks are run, for the most part, by low-paid public service operators. These individuals required considerable interpersonal interaction to maintain their sense of morale and their commitment to service. Although the Kangaroo network is relatively new, and so requires considerable administrative traffic to establish procedures and plan network development, 50( administration is clearly excessive. The Micronesia network (17.6\% content) and USP Net $(73.2 \%)$ indicate that a mix of $80 \%$ content to $20 \%$ administration is a reachable goal for ATS-1 networks. This would set $60 \%$ as the target throughput, which is not bad for a simplex system (See Abramson, 1977 ).

Design efficiency is equally low, with the exception of the goal to operate in teleconference mode, as opposed to point-to-point traffic which might 
be construed as competition for government or commercial carriers in the region. The USP net $(87.7 \%)$ indicates that a goal of $90 \%$ multi-mode conferencing is reachable. Similarly, the Kangaroo network, with $69.6 \%$ participants and only $30.4 \%$ operator traffic, indicates that $75 \%$ participants is not an unreasonable target.

No network does very well at the goal of serving primarily Pacific islanders, and it is likely that none ever will. First, expatriates have a stronger motivation to talk to the outside world, in order to keep in touch with their home cultures. Second, most indigenous users come to the network to reach non-islander expertise in American, Australian and New Zealand educational, technical and social service institutions. With this in mind, 50\% islander traffic seems a reasonable target.

If all of the "reachable goals" discussed above are used to compute a success index, the idealised ATS-1 network would have an Sl of .20. Dropping the islander consideration (for the Australian network) the goal SI is .40.

$\begin{array}{llc}\text { Scheduling efficiency } & \text { (\% of time used) } & 75 \% \\ \text { Admin. Efficiency } & \text { (\% of time for content) } & 80 \% \\ \text { Design Efficiency } & \text { (\% Teleconference) } & 90 \% \\ & \text { (\% participants) } & 75 \% \\ & \text { (\% islanders) } & 50 \%\end{array}$

An ideal / real ratio can then be computed to give an indication of network effectiveness of $55 \%$ for the Micronesia and PEACESAT networks (7/20), $42.5 \%$ for the Kangaroo net $(17 / 40)$ and $55 \%$ for the University of the South Pacific (11/20). Clearly, there is significant room for improvement.

Some cosmetic improvements could be made immediately. For example, the New Zealand terminal, which accounts for a considerable portion $(25.6 \%)$ of the Peacesat network, could be run by a Maori rather than a Caucasian, and the Hawaiian terminals, which account for $22 \%$ of all ATS1 traffic, could be staffed by native Hawaiians, rather than Caucasian and Japanese-Americans. This would improve the "Islander" traffic considerably, but it seems a bit of a racist over-reaction. For example, does Stuart Kingan, a New Zealander who has made his home in the Cook Islands for the past 25 years count as an Islander or Caucasian? How should Dr. Steven Seumahu, a native Spice-Islander who has made his permanent home in Australia, be classified?

Similar minor adjustments can be made in the schedule to remove the odd hour or two which is consistently unused from network responsibility. Although this would improve the "Network" throughput, and it would do nothing for the overall satellite thoughput, and it would considerably limit the growth potential of the networks by reducing their flexibility and planning room. 
Real and permanent improvements will require deeper thinking and coordination. Are there users in French Polynesia who could make better use of the morning time which is too early for most of the Pacific? Do the Australian and Micronesian networks need technical assistance to finalise their plans to use the evening (0800-1100 GMT) times, or could potential users in Asia make better use of these time slots? chat kind of administrative procedures, coupled with data transmission, could be devised to reduce the amount of on-air administrative time? chat kinds of public relations out-reach and user training could be devised to increase the activity of conference participants?

Answers to the hard questions that are needed to bring about real and permanent improvements in ATS-1 traffic are being continually sought by terminal operators and network management, and the process might be hastened by some assistance from NASA and the University of Hawaii Social Science Research Institute, which handles the scheduling of ATS-1 for NASA. Organisations such as the Pacific Telecommunication Council, New Zealand's Department of Industrial and Scientific Research, America's Public Service Satellite Consortium and Australia's Satellite Users Organisation all have considerable expertise to assist in this endeavour.

However, no amount of work will still the basic criticism that ATS-1 is an "elitist" medium. With 50 terminals sharing overlapping memberships in five different networks on a single channel satellite operating in simplex mode, it can never be anything else. It cannot hope to be an open-access interpersonal medium, such as the telephone, nor can it act as a mass medium, such as a conventional radio station. ATS-1 is a "quasi-mass" medium (see Regan, 1975), in that this network splits nearly every difference between mass media (such as a radio station) and interpersonal media (such as the telephone) squarely down the middle. The same will be true for educational networks over INTELSAT, AUSSAT, or even HFradio.

1. Mass media are public; interpersonal media are private. ATS-1 exchanges are not public, in that they are limited to those actually in the studio, but neither are they private, since anyone who wants to come to the studio is welcome and any earth station can listen in, regardless of whether they are formally participating.

2. Interpersonal media use more idiosyncratic codes; mass media codes are more universal. The ATS- 1 networks use a universal code (usually English), but one which is not shared equally among all participants. In addition, individual exchange groups have their own jargon, and all exchanges tend to use "ham-radio" slang.

3. Interpersonal media are continuing; mass media are immediate. ATS-1 exchanges are on-going, co-operative efforts, rather than one-shot programs, but they cannot be started, stopped and rescheduled with the same spontaneity that is possible in a small group that all live in the same community. 
4. Access to interpersonal media is open; mass media access is restricted. In theory, ATS-1 exchanges are open to anyone. In practice, they are limited to those who stop by the studio on their own, or who are known to an operator to be interested in a given subject.

5. Interpersonal media require only common skills needed to speak on a simplex network (such as saying "over" at the end of transmissions, or making frequent "copy checks" during long expositions); the frequently poor signal quality requires special listening skills to separate the message from the channel noise.

6. Interpersonal media are controlled by ad hoc leaders; mass media require permanent professional staff. While ATS-1 networks do not require an operator once an exchange has begun, operators are required to monitor the network, to handle scheduling and to locate people who might be interested in the exchanges.

7. Interpersonal media are low cost; mass media are expensive. Although NASA allows free use of ATS-1, the cheapest earth station for this satellite is about $\$ 2000$. This is not a lot of money, but it is certainly beyond the reach of most individuals in the Pacific islands.

8. Interpersonal media are "next-door"; mass media are distant. On most islands, ATS-1 studios are within walking distance of the majority of the residents, while the nearest daily newspaper may be several hundreds miles away. Where telephone patching is permitted, the satellite as far away as the nearest telephone.

9. Interpersonal media audiences are homogenous; mass media audiences are heterogeneous. Participants frequently have an extremely wide range of education, cultural background, and linguistic ability, yet are homogeneous in their interest in the subject matter at hand.

10. Interpersonal media provide rapid and extensive feedback; mass media feedback is little and slow. All networks are designed to support interactive teleconferencing, which allows immediate and extensive feedback. However, sessions with five or more active terminals are forced to curtail the natural flow of discussion, in order to ensure enough time to accomplish the agenda.

Each of these factors, both separately and in combination, work to decrease system throughput and to reduce design efficiency, but the ATS1 networks, or any teleconferencing network with severely limited channel space, cannot operate in any other way. These limitations suggest specific design criteria for educational networks. Several educational communication systems around the world are experimenting with used and ATS-1 model on more sophisticated satellites (Block, and others, 1984 no reference in Bibliography). Unless these limitations are taken into consideration, these efforts are likely to fail. The specific implications of the ATS-1 model for AUSSAT systems are discussed in another paper. (Lange, 1984). 


\section{Conclusion}

The ATS-1 satellite networks are not as efficient as they could be. Some minor improvements, outlined in this paper, could be made immediately. Others will require considerable thought and effort, including help from organisations outside the Pacific which have wide experience in communication networks. However, since the satellite is limited to a single voice channel which is shared among some fifty terminals, and since current users want a teleconferencing system in preference to other uses, they must operate somewhat inefficiently, if they are to operate at all. The same is true for other networks based on the ATS-1 model.

\section{References}

Norm Abramson, 1977, "The Throughput of Packet Broadcasting Channels". IEEE Transactions on Communications, 25:1, pp. 117-128.

Gilda Bensted, Dick Northcott and Peter McMechan, 1975, "Report for the First Experimental Year: USP Satellite Communication Project" Suva: University of the South Pacific Extension Service.

Carlos Boker, 1982 report on Pacific Islands inspection tour for the University of Hawaii Communication Department and Social Science Research Institute (unpublished).

John Bystrom and Paul Yuen, 1971, "Report and Request to the National Aeronautics and Space Administration" (Honolulu: University of Hawaii Communication Department).

Graham Davey, 1985, Speech in Plenary Session of the Pacific Telecommunication Conference, Honolulu (unpublished).

Department of the Interior, Trust Territories of the Pacific and Public Service Satellite Consortium, 1977, "Application for Use of ATS-1" Washington: Department of the Interior.

Paul Eden and Otis Brown, 1976, "Application for the Use of ATS-1 and ATS-3 for an Oceanographic Communication Network". University of Miami (unpublished).

James Lange, 1983, "From PEACESAT To INTELSAT in the Pacific". Media Development, XXX: 4, pp. 24-25.

James Lange, 1984, "The ATS-1 Communications Model". Prometheus (in press).

Chris Plante, 1980, "PEACESAT: A Wolf in Sheep's Clothing". Journal of the Centre for Advanced TV Studies, Vol.8. pp. 22-25.

Joey Regan, 1978 "Quasi-mass Media" paper presented at the Speech Communication Association Annual Meeting (unpublished).

University of the South Pacific Extension Studies, 1981, "Report to Council" (Suva: USP internal document -- unpublished).

Support for this research was provided by the East-West Communication Institute, the Social Science Research Institute of the University of Hawaii, and the University of Guam.

Please cite as: Lange, J. C. (1985). The efficiency of educational communications networks: ATS-1 as a quasi-mass medium. Australian Journal of Educational Technology, 1(1), 76-86. http:/ / www.ascilite.org.au/ajet/ajet1/lange.html 